\title{
PROPERTIES OF CARBON NANOTUBES AND THEIR USE IN POTENTIAL APPLICATIONS
}

Many laboratories in the world are doing research in the field of nanotechnology. Among lot of nanomaterials carbon nanotubes became very popular because of their unique properties which could be used in many applications. But first, lot of problems with their preparation need to be solved.

\section{Structure}

Carbon nanotubes (CNTs) are very promising material because of their extraordinary properties - electronic, mechanical and optical. These properties are given by the structure of the CNTs. We can imagine a nanotube as a graphite plane rolled up to a cylinder. It can be opened or closed at one or both ends of the cylinder. Each nanotube is characterized by the chiral vector $C_{h}$ and the chiral angle $\theta$ (Fig. 1). The chiral vector: $C_{h}=n a_{1}+m a_{2}$, where $a_{1}, a_{2}$ are the lattice vectors and $n, m$ are integers, is given on the circumference of the nanotube. [1]

There are three types of structures: $\operatorname{armchair}\left(\theta=45^{\circ}, n=m\right)$, ,zig-zag" $\left(\theta=0^{\circ}, m=0\right)$ and chiral $\left(\theta=0-30^{\circ}, n \neq m\right)$. CNTs are divided into two main groups: Single Wall Carbon Nanotubes (SWCNTs) and Multi Wall Carbon Nanotubes (MWCNTs).

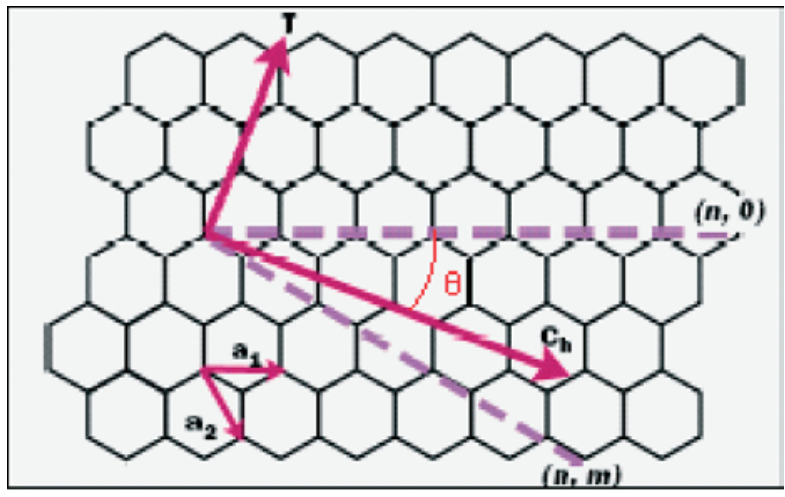

Fig. 1 CNT structure [1]

\section{Properties}

The most interesting properties of carbon nanotubes and their potential use in some applications are given in Table 1.
Properties of CNTs and their use in potential applications Table 1

\begin{tabular}{|c|c|c|c|}
\hline \multirow[t]{2}{*}{ properties } & electrical & physical & mechanical \\
\hline & $\begin{array}{l}\text { - field emission } \\
\text { - conductivity }\end{array}$ & $\begin{array}{l}\text { - thermally } \\
\text { stable } \\
\text { - large surface } \\
\text { area } \\
\text { - cavities }\end{array}$ & $\begin{array}{l}\text { - mechanical } \\
\text { strength } \\
\text { - elasticity }\end{array}$ \\
\hline applications & $\begin{array}{l}\text { - electronic } \\
\text { nanodevices } \\
\text { - emitors for } \\
\text { displays } \\
\text { - AFM tips } \\
\text { - sensors }\end{array}$ & $\begin{array}{l}\text { - gas sensors } \\
\text { - hydrogen } \\
\text { storage } \\
\text { - electrodes for } \\
\text { bateries and } \\
\text { fuel cells } \\
\text { - composit } \\
\text { materials }\end{array}$ & $\begin{array}{l}\text { - STM/AFM } \\
\text { tips } \\
\text { - instruments } \\
\text { for nanomani- } \\
\text { pulation } \\
\text { - composit } \\
\text { materials }\end{array}$ \\
\hline
\end{tabular}

The most important property for the use in the electronic applications is the conductivity of carbon nanotubes. Depending on the structure, they can be either metallic or semiconducting. Because of their small diameter, they represent nearly ideal onedimensional system. So the nanotubes do not allow the scattering of charge carriers by defects or phonons and they exhibit lower resistivity than conventional systems. Electrical transport in CNTs is supposed to be ballistic, so the energy dissipation in the CNT is minimal and the dissipated power density is lower [2]. CNTs can withstand current densities up to $10^{7} \mathrm{~A} / \mathrm{cm}^{2}$ [3]. One of the potential applications is CNTFET, which is an analogue of the silicon MOSFET, where the silicon channel is replaced by a SWCNT. Gold electrodes (source and drain) were fabricated on the $\mathrm{SiO}_{2}$ covered silicon wafer [2]. SWCNT (channel) was then manipulated to bridge the electrodes. The heavily doped wafer with the silicon dioxide served as the gate electrode and gate dielectric. This nanoelectronic device had a lot of disadvantages such as high contact resistance and low on-current. And all transistors, created using one SWCNT, had to be on or off at the same time. These problems were solved by the preparation of top-gated CNTFET and the fabrication of a better metal-CNT contact.

\footnotetext{
* A. Vojačková

Faculty of Electrical Engineering and Information Technology, Slovak University of Technology, Ilkovičova 3, 81219 Bratislava, Slovakia

E-mail: anna.vojackova@stuba.sk
} 
Very promising property of carbon nanotubes is their field emission. If voltage is applied to carbon nanotubes in the electric field formed, they emit electrons. This makes nanotubes a very promising material for cold electron emitters. Electron emitters for SEM, TEM, flat displays and cathode ray lamps have to meet some strict criteria (stable emission current, small energy spread). Compared to conventional electron emitters, carbon nanotubes have the best parameters [4]. The next advantage of CNTs field emitters is low voltage needed for field emission. For emission currents of $10^{-7} \mathrm{~A}$ applied voltage of $10^{2} \mathrm{~V}$ is needed [3].

The most interesting mechanical parameter is Young's modulus, which is a measure of material's elastic strength. The modulus is determined by the $\mathrm{C}-\mathrm{C}$ bonds within the walls. Its value for CNTs is about $1 \mathrm{TPa}$ [3]. Another amazing property is elastic deformation - the deformation disappears when the load, causing this deformation, is removed. This is caused by the ability of carbon atoms in the walls to change their hybridization. An AFM tip with CNT can be fabricated by manually attaching a nanotube to the
Si tip or by direct growth of a CNT onto the Si tip. Extremely stable MWCNT tips with small diameters $(<30 \mathrm{~nm})$ were fabricated. The mass production technology of wafer-scale CNT AFM tips was developed [5].

\section{Applications}

These are just few applications which use the properties of carbon nanotubes. There are many other possible applications such as nanocomposites [6][7], CNTs films for sensor structures [8][9], hydrogen storage medium [10] etc. Most of these applications are under development. The most important step is the efficient preparation of CNTs with the possibility to control their properties with aspect to the desired application.

\section{CNTs at FEI STU}

At the Department of Microelectronics FEI STU in Bratislava there is a group of researchers trying to prepare arrays of oriented

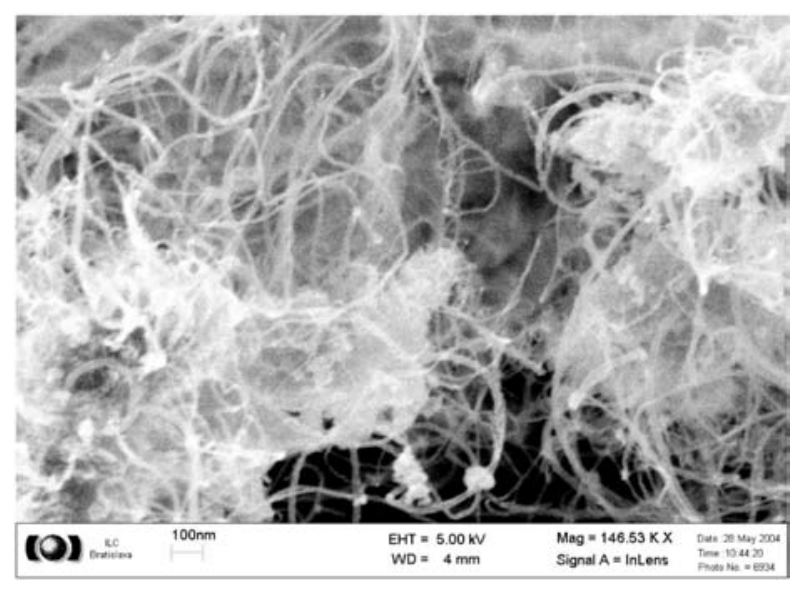

a)

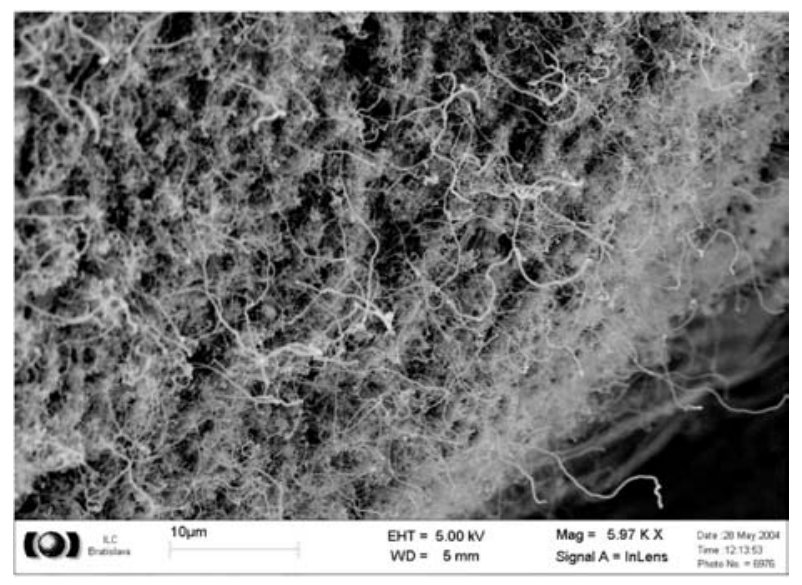

b)

Fig. 2 Carbon nanotubes grown on non-conducting substrates magnified a) $146530 x$ and b) $5970 x$

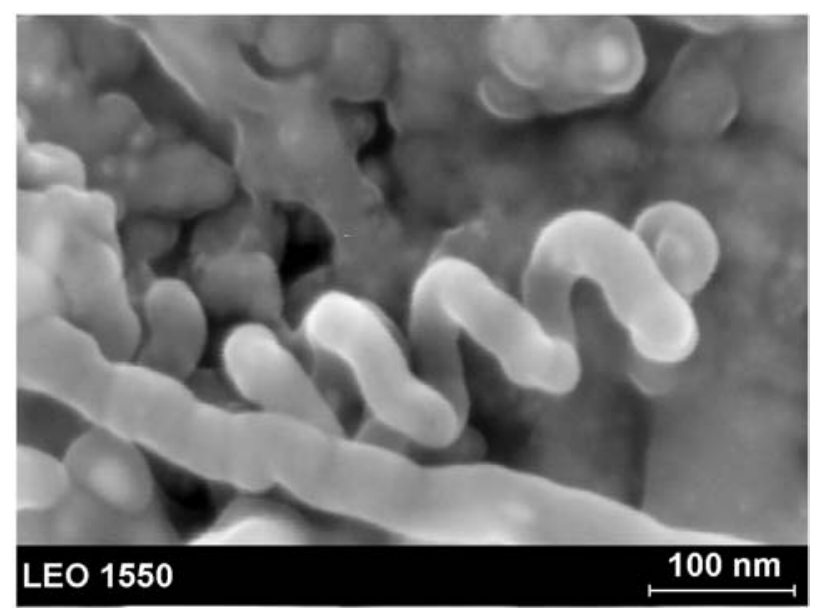

Fig. 3 Carbon nanotubes grown on conducting substrates 
carbon nanotubes on various substrates with good emission characteristics. Arrays of non-oriented carbon nanotubes on non-conducting and conducting substrates were prepared (Figs. 2 and 3). On the conducting samples measurements of electron emission were carried out. All the samples were studied using Raman Spec- troscopy and Scanning Electron Microscopy in cooperation with the International Laser Centre. This work is supported by Grants of the Ministry of Education of the Slovak Republic VEGA 1/3034/06, VEGA 1/2040/05 and VTP 1002/2003.

\section{References:}

[1] LERNER, E. J.: Putting Nanotubes to Work. The Industrial Physicist [online] December, 1999, Vol. 5, No. 6, 22-25. Available on internet: 〈http://www.aip.org/tip/INPHFA/vol-5/iss-6/p22.pdf>

[2] AVOURIS, P., APPENZELLER, J.: Electronics and Optoelectronics with Carbon Nanotubes. The Industrial Physicist [online] July, 2004, Vol. 10, No. 3, 18-21. Available on internet: 〈http://www.aip.org/tip/INPHFA/vol-10/iss-3/p18.pdf>

[3] SCHOENEBERGER, CH., FORRÓ, L.: Multiwall Carbon Nanotubes. Physics World [online] June, 2000. Available on Internet: $\langle$ http://physicsweb.org/articles/world/13/6/8>

[4] DE JONGE, N., LAMY, Y., SCHOOTS, K., OOSTERKAMP, T. H.: High Brightness Electron Beam from a Multi-walled Carbon Nanotube. Nature [online] November,2002, Vol. 420, 393-395. Available on internet: <http://www.research.philips.com/technologies/light_dev_microsys/carbonnt/ downloads/nature2002_420_393_39.pdf>

[5] NGUYEN, C. V., YE, Q., MEYYAPPAN, M.: Carbon Nanotube Tips for Scanning Probe Microscopy: Fabrication and High Aspect Ratio Nanometrology. Meas. Sci. Technol. 16 (2005) 2138-2146. [online] Available on internet: <http://www.iop.org/EJ/S/3/670/ PYt91aqgIfJuoh976 Az3ww/article/0957-0233/16/11/003/mst5_11_003.pdf>

[6] SCHARTEL, B., PÖTSCHKE, P., KNOLL, U., ABDEL-GOAD, M.: Fire Behaviour of Polyamide 6/Multiwall Carbon Nanotube Nanocomposites. European Polymer Journal 41 (2005) 1061-1070. [online] Available on internet: <http://www.fibrils.com/PDFs/ P.\%20Potschke\%20Euro \%20Polymer\%20Journal\%2041(2005)1061.pdf>

[7] ROBEL, I., BUNKER, B. A., KAMAT, P. V.: Single-Walled Carbon Nanotube-CdS Nanocomposites as Light-Harvesting Assemblies: Photoinduced Charge-Transfer Interactions. Adv. Mater. 17 (2005) 2458-2463. [online] Available on internet: < http://www3.interscience. wiley.com/cgi-bin/fulltext/111090082/PDFSTART>

[8] SOTIROPOULOU, S., CHANIOTAKIS, N. A.: Carbon Nanotube Array-based Biosensor. Anal Bioanal Chem 375 (2003) 103-105. [online] Available on internet: < http://lib.store.yahoo.com/ lib/nanolab2000/biosensor.pdf>

[9] PENZA, M., CASSANO, G., AVERSA, P., CUSANO, A., CUTOLO, A., GIORDANO, M., NICOLAIS, L.: Carbon Nanotube Acoustic and Optical Sensors for Volatile Organic Compound Detection. Nanotechnology 16 (2005) 2536-2547. [online] Available on internet: 〈http://www.iop.org/EJ/article/0957-4484/16/11/013/nano5_11_013.pdf〉

[10] CHAN, S. P., CHEN, G., GONG, X. G., LIU, Z. F.: Chemisorption of Hydrogen Molecules on Carbon Nanotubes under High Pressure. Physical Review Letters [online] November, 2001, Vol. 87, No. 20. Available on internet: http://www.eng.uc.edu/ gbeaucag/ Classes/Nanopowders/ CarbonBasedNanoPowders/ReistenbergReferences/chemisorption.pdf 